Authors' accepted manuscript

Article published in The International Journal of Advanced Manufacturing Technology, vol. 113, pages 2447-2460 (2021)

Version of record: https://doi.org/10.1007/s00170-021-06807-y

The International Joumal of Advanced Manufacturing Technology

https://doi.org/10.1007/s00170-021-06807-y

ORIGINAL ARTICLE

\title{
Optimization of furnace residence time and loading pattern during heat treatment of large size forgings
}

Nima Bohlooli Arkhazloo ${ }^{1}$. Farzad Bazdidi-Tehrani ${ }^{2}$ - Jean-Benoît Morin ${ }^{3}$ - Mohammad Jahazi ${ }^{4}$

Received: 7 December 2020 / Accepted: 8 February 2021

(C) The Author(s), under exclusive licence to Springer-Verlag London Ltd. part of Springer Nature 2021 


\section{Optimization of furnace residence time and loading pattern during heat treatment of large size forgings}

Nima Bohlooli Arkhazloo ${ }^{1, *}$, Farzad Bazdidi-Tehrani², Jean-Benoît Morin³ and Mohammad

$$
\text { Jahazi }^{4}
$$

${ }^{1}$ Département de Génie Mécanique, École de Technologie Supérieure, Montréal, H3C 1K3, Canada, Email : nima.bohlooli-arkhazloo.1@ens.etsmtl.ca

${ }^{2}$ School of Mechanical Engineering, Iran University of Science and Technology, Tehran 16846-13114, Iran, Email: bazdid@iust.ac.ir

${ }^{3}$ Finkl Steel Inc., 100 McCarthy, Saint-Joseph-de-Sorel, QC J3R 3M8, Canada, Email: jbmorin@finkl.com

${ }^{4}$ Département de Génie Mécanique, École de Technologie Supériere, Montréal, H3C 1K3, Canada, Email : mohammad.jahazi@etsmtl.ca

*Address correspondence to Dr. Nima Bohlooli Arkhazloo, E-mail: nima.bohlooli-arkhazloo.1@ens.etsmtl.ca, Phone number: +1514 9950161,

Fax number: +1514 396-8530 


\begin{abstract}
A combination of unsteady 3D CFD simulations and experimental temperature measurements was employed to determine the effect of loading patterns on the temperature distribution within steel forgings inside a gas-fired heat treatment furnace. This was aimed to obtain a more homogenous temperature distribution. Besides, a hybrid methodology using 3D numerical simulations and a high-resolution dilatometer allowed improving residence time of forgings inside the heat treatment furnace. The influence of the loading patterns and skids on temperature distribution and residence time of forgings was examined using thermal analysis four different loading patterns. Comprehensive unsteady thermal analysis of the products heating allowed quantifying the impact of skids usage and their dimensions on the extent of the uniformity of temperature distribution. The results were interpreted in terms of the inter-relationship between the skids usage, their geometry, absorbed radiation and convective heat fluxes. The analysis showed that temperature non-uniformities of up to $331 \mathrm{~K}$ could be produced for non-optimum loading patterns. Using the developed CFD approach it was possible to reduce the temperature non-uniformity of different sizes of blocks up to $32 \%$ via changing the loading pattern inside the furnace. Further, the slab's residence time was improved by almost $15.5 \%$ when employing the proposed hybrid approach. This approach could directly be applied to the optimization of different heat treatment cycles of forged blocks in different grades of steels.
\end{abstract}

Keywords: Loading pattern, Temperature uniformity, Residence time, Hybrid approach, Experimental measurements, CFD simulation 


\section{Nomenclature}

\begin{tabular}{|c|c|c|c|}
\hline $3 \mathrm{D}$ & Three dimensional & $T$ & Temperature $(\mathrm{K})$ \\
\hline CFD & Computational Fluid Dynamics & $t_{T}$ & Total heating time \\
\hline DO & Discrete ordinates model & $u$ & Velocity $(\mathrm{m} / \mathrm{s})$ \\
\hline E & Energy $(\mathrm{J})$ & $u_{i}$ & $\begin{array}{l}\text { Favre-averaged velocity in tensor } \\
\text { notation }\end{array}$ \\
\hline$h$ & Enthalpy $(j / k g)$ & $Y$ & Mass fraction of species \\
\hline$J_{i}^{z}$ & Diffusive flux of chemical species & $x, y, z$ & Direction of coordinate axes \\
\hline $\mathrm{HRC}$ & Rockwell C hardness & $z$ & $z_{t h}$ species \\
\hline$k$ & Turbulence kinetic energy $\left(\mathrm{m}^{2} / \mathrm{s}^{2}\right)$ & $\varepsilon$ & Turbulence dissipation rate $\left(\mathrm{m}^{2} / \mathrm{s}^{3}\right)$ \\
\hline$k_{e f f}$ & Effective thermal conductivity & $\tau_{i j}$ & Viscous stress tensor \\
\hline$p$ & Pressure $(\mathrm{Pa})$ & $v$ & Kinematic Viscosity $\left(m^{2} / s\right)$ \\
\hline$R_{z}$ & Production rate of $z_{t h}$ component & $\mu_{t}$ & Turbulent eddy viscosity $(\mathrm{kg} . \mathrm{m} / \mathrm{s}$ ) \\
\hline$R_{z, r}$ & Production rate of $z_{t h}$ component & $\rho$ & Density $\left(\mathrm{kg} / \mathrm{m}^{3}\right)$ \\
\hline$S_{z}$ & Source term of $z_{t h}$ component production & $\rho \overline{u_{i}^{\prime} u_{j}^{\prime}}$ & Reynolds stress $\left(\mathrm{kg} / \mathrm{m} . \mathrm{s}^{2}\right)$ \\
\hline SK & Single Skid & Superscripts & \\
\hline DSK & Double Skid & ' & $\begin{array}{l}\text { Fluctuations with respect to a Reynolds } \\
\text { averaging }\end{array}$ \\
\hline SKC & Single Skid + Central spacer skid & Subscripts & \\
\hline DSKC & Double skid + Central spacer skid & $i, j, k$ & $\begin{array}{l}\text { Tonsorial indices unless otherwise } \\
\text { stated }\end{array}$ \\
\hline$S c$ & Schmidt number & & \\
\hline$q_{s}$ & The generic source term & & \\
\hline $\operatorname{Re}$ & Reynolds number $(u d / v)$ & & \\
\hline RTE & Radiative transport equation & & \\
\hline$t$ & Time (s) & & \\
\hline
\end{tabular}




\section{Introduction}

Gas-fired furnaces are extensively used in the steel industry in the heat treatment process. Specifically, in the case of heavy forgings made of high strength steels, a heat treatment process called Quench and Temper (Q\&T) is used to obtain the desired mechanical properties (e.g., hardness)[1]. The Q\&T process is carried out in two steps: initially the parts are heated to a certain temperature and hold for a period of time before being quenched in water. In the second step (tempering) the parts are heated to a lower temperature (non-isothermal tempering) and kept for a period of time (isothermal tempering) before being air cooled. It is of paramount importance to ensure a high-quality heat treatment operation as major microstructural changes (grain refinement, phase transformation, etc.) take place at this stage [2]. These microstructural changes have a determining effect on the hardness, as the most common qualification criteria for successful heat treatment in the steel industry. According to Janjušević et al. [3] the final mechanical properties and microstructural features are affected significantly by tempering temperature and holding time inside the furnace. Therefore, uniformity of the heating process, in other words, the temperature distribution's uniformity during the non-isothermal tempering up to the target temperature is of great importance for the quality of final products [4], specifically for large size products. However, considering that parts, are rarely single loaded in the furnace, their loading pattern (e.g. distances between the parts, stacking mode, etc.) as well as furnace geometry (burners' and skids' positions), will influence temperature evolution within their volume resulting in non-uniform temperature distribution that may affect the final properties. Possible use of longer holding times is not a viable solution as it will bring other mechanical properties alterations and is not energy friendly. Hao et al. [5] in their numerical analysis of heating process in a vacuum heat treatment furnace pointed out that the predicting, controlling and consequently optimizing the heating process (or the transient temperature of the part as a function of the furnace temperature) and the related thermal 
interactions and subsequently possible reduction in the tempering process time, is a necessary task for energy saving and quality control. However, an exact prediction of the furnace temperature distribution and, consequently, the temperature experienced by the product would require a more fundamental understanding of the interactions between heat transfer parameters, process parameters and parts configurations within the furnace. At the present time such data in thermal analysis of large size products heating characteristics is not available and therefore often empirical correlations are used to estimate the heat treatment cycle parameters [2]. These correlations are usually defined as a function of the total furnace load and selected loading patterns of the parts inside the furnace [6]. Hence, they show large deviations in the case of multiple loadings and complex furnace configurations [5].

On the other hand, in most of the studies and evaluations in the field of metallurgy, nonisothermal tempering procedure was simplified assuming a constant heating rates rather than a variable one which is actually experienced by the products in the real production cycle. For example studies like those of Chenge et al. [7], Ding et al. [8], Kekana et al. [9], and BakhsheshiRad et al. [10] focusing on different metallurgical aspects like microstructure evolutions, phase transformations, carbides precipitation during tempering process and their subsequent effect on the mechanical properties of the product, used constant heating rates in their investigations. The problem is more acute in the case of large size products (that encompass high temperature gradient from one end to another) at high temperatures due to operational difficulties and high costs of experimentation. Therefore, employing a constant temperature and time in the correlations such as Hollomon-Jaffe [3] may result in deviation from what is really experienced by the large size forgings during the whole tempering process. 
While both analytical and numerical methods could be used to study the heating process in the non-isothermal tempering stage, limitations of analytical methods in solving coupled non-linear phenomena (i.e., turbulent combustion along with conjugate heat transfer and fluid flow) do not allow their effective use in these cases. For example, Gao et al. [4] using a semi-analytical study on the estimation of equilibrium time during the heat treatment process of arbitrary shape products, reported inconsistencies up to $20 \%$ for the Biot number between 0.1 and 5. Computational fluid dynamics (CFD) comprising various numerical methods has become in recent years a very cost effective and reliable technique to study the thermal interactions in different manufacturing processes including industrial furnaces [11-15]. Specifically, Wang et al. [16] predicted the temperature field of gas quenching furnace using CFD simulation and Cosentino et al. [17] investigated the non-uniform quenching effect on the product properties. Recommendations for analysis of the heat treatment process in vacuum quenching furnaces were proposed by Cosention et al. [17] and Hao et al. [5] who investigated temperature distributions of products inside a gasquenching and vacuumed heat treatment furnace, respectively.

However, due to the complexity of the reactive flow analysis inside the gas-fired furnaces, little data is available in the literature. Studies comprising those of Harish and Dutta [18] concentrated on the radiation simulation of slab reheat furnace provided insight into the temperature distribution and thermal interactions inside gas-fired furnaces. Recently, Liu et al. [19] using CFD, with a focus on modeling of pulse combustion in a reheating furnace, proposed a model for increasing the temperature uniformity of products in these furnaces. While, Mayr et al. [20] proposed and validated a one-step steady state CFD approach for process optimization. Also, Tang et al. [21] employing an approach consisting of 3D CFD and 2D finite difference methods (validated by experimental measurements) could report reliable results in the prediction of heating 
history of products within a pusher type gas-fired furnace. Lin et al. [22] also proposed a novel two-dimensional numerical model to estimate the fuel mass flow rate in walking beam type reheating furnace along with the three-dimensional CFD simulation of the process.

However, continuous gas-fired furnaces, due to their shorter processing time (regularly 2 hours [21]) in comparison with the large size heat treating furnaces (24-48 hours in the case of large size products [23], require lower computational time for transient simulation. Hence, little information is available regarding the transient studies of the real-scale gas-fired heat treatment furnaces. The existing studies have been mainly focused either on small- to medium-scale gasfired furnaces or simplified steady-state simulations. For instance, Yang et al. [24] concentrating on the numerical simulation validated by experimental measurement, studied the performance of small-scale gas-fired mobile heat treatment furnaces. Schluckner et al. [25] used a CFD model to predict the effect of oxygen enriched combustion atmosphere on the transient scale formation of steels in a lab scale heat treatment furnace. Prieler et al. [26] investigated the heat distribution of a laboratory-scale furnace and proved the applicability of steady flamelet approach in the simulation of gas-fired furnaces. Also, Mayr et al. [27] investigating the heat distribution in a semi-industrial gas-fired furnace proposed a time saving combustion modeling approach in this application. Recently Jóźwiak et al. [28] investigated the effect of syngas usage on the transient heating of product in a gas-fired furnace.

On the process optimization side and its related parameters, recently, Rezazadeh et al. [29] studied the effect of burner configuration on the temperature uniformity of products in an industrial scale gas-fired heat treatment furnace. Also, Arkhazloo et al. [30] reported on the experimental and numerical analyses of the heating process of large size forged ingots inside a gas-fired furnace. Comprehensive experimental analysis of instrumented large size ingot and gas-fired furnace 
temperature's history proved that large-scale products can affect the furnace temperature's uniformity and consequently products' heating uniformity. A full-scale three-dimensional (3D) model of the process revealed that the identified non-uniform heating of the large-scale products had a relationship with the fluid flow structure, geometrical parameters of the furnace (including burner locations) and loading patterns of ingots (including their relative locations and distances). The effect of vortical structures and loading pattern on the heat treatment process and temperature history of small scale products had been mentioned in the numerical study of Wang and Shang [31] who investigated the flow and heat exchange in the high-pressure gas quenching chamber. Korad et al.'s [6] concentrating on the metallurgical aspects and toward reducing the process cost employed the steady state CFD simulations of indirect fired homogenization furnace (used for aluminum billet treatment). Their results showed that different billets stacked in the furnace experienced different temperature distributions (temperature non-uniformity) as a result of loading pattern inside the furnace during the non-isothermal tempering. Macchion et al. [32] in a CFD simulation of gas quenching chamber of small parts pointed out that the position of parts inside the furnace could significantly affect the temperature uniformity of products during the heat treatment furnaces. Also, Kang and Rong [2] using CFD simulations investigated the heating history (non-isothermal tempering) of two different loading patterns of small size parts inside a vacuum heat treatment furnace. Their study revealed that the loading pattern even in small size products could change the heating history of the parts and furnace performance. However, up to now, little data is available on the interactions between heat transfer parameters, stacking strategy, heat treatment process variables (specifically temperature uniformity and heating time in nonisothermal tempering) in relation to loading pattern of forgings inside gas-fired furnaces. 
Besides, most of the studies investigated the effect of constant heating rates rather than a series of a variable heating rates (resulting in real temperature history experienced by the products inside the furnace) and subsequent certain holding times on the final mechanical properties of the steels during the tempering process [33-36]. For example, Ray et al. [37] and Wang et al. [38] studied the effect of heat treatment process on the microstructure and mechanical properties of HSLA100 steel and H13 steel using constant heat rates for the tempering process. Recently, Wu et al. [39] investigated the effect of tempering mode and reheating rate on the mechanical properties of high-strength low alloy steels using two different constant heating rates, representing the conventional and induction reheating. Among rarely found studies with consideration of transient heating history, Miloan et al. [40] recently investigated the heat treatment of EN 1.4136 stainlesssteel using transient heating rates (between $0.5-1.5{ }^{\circ} \mathrm{C} / \mathrm{s}$ ) on a laboratory scale solar furnace. However, simultaneous analysis of isothermal and non-isothermal tempering history (with variable heating rates) of large size forgings inside gas-fired furnaces in order to reduce the residence time of the products has not been addressed in the literature.

The present paper reports on an investigation aiming to address the above challenges using 3D CFD modeling complemented with experimental validation. This is not only aimed to have maximum temperature distribution's uniformity and similar heating rates, but also to reduce the time to reach the target temperature during the non-isothermal tempering stage. Besides, a new approach combining 3D CFD numerical predictions and high-resolution dilatometry was developed that allowed further reducing the residence time of the forgings during isothermal tempering stage. The optimization in this stage was conducted 


\section{Loading patterns}

Fig. 1 illustrates the furnace and the four different loading patterns used for the CFD simulations. The studied furnace was a $3.05 \times 3.28 \times 8.83\left(\mathrm{~m}^{3}\right)$ batch type gas-fired furnace. The furnace was heated by 18 high-velocity cup burners [41] including 9 upper burners (located on the uppers section of the furnace left wall) and 9 lower burners (installed in the lower section of the furnace right wall).
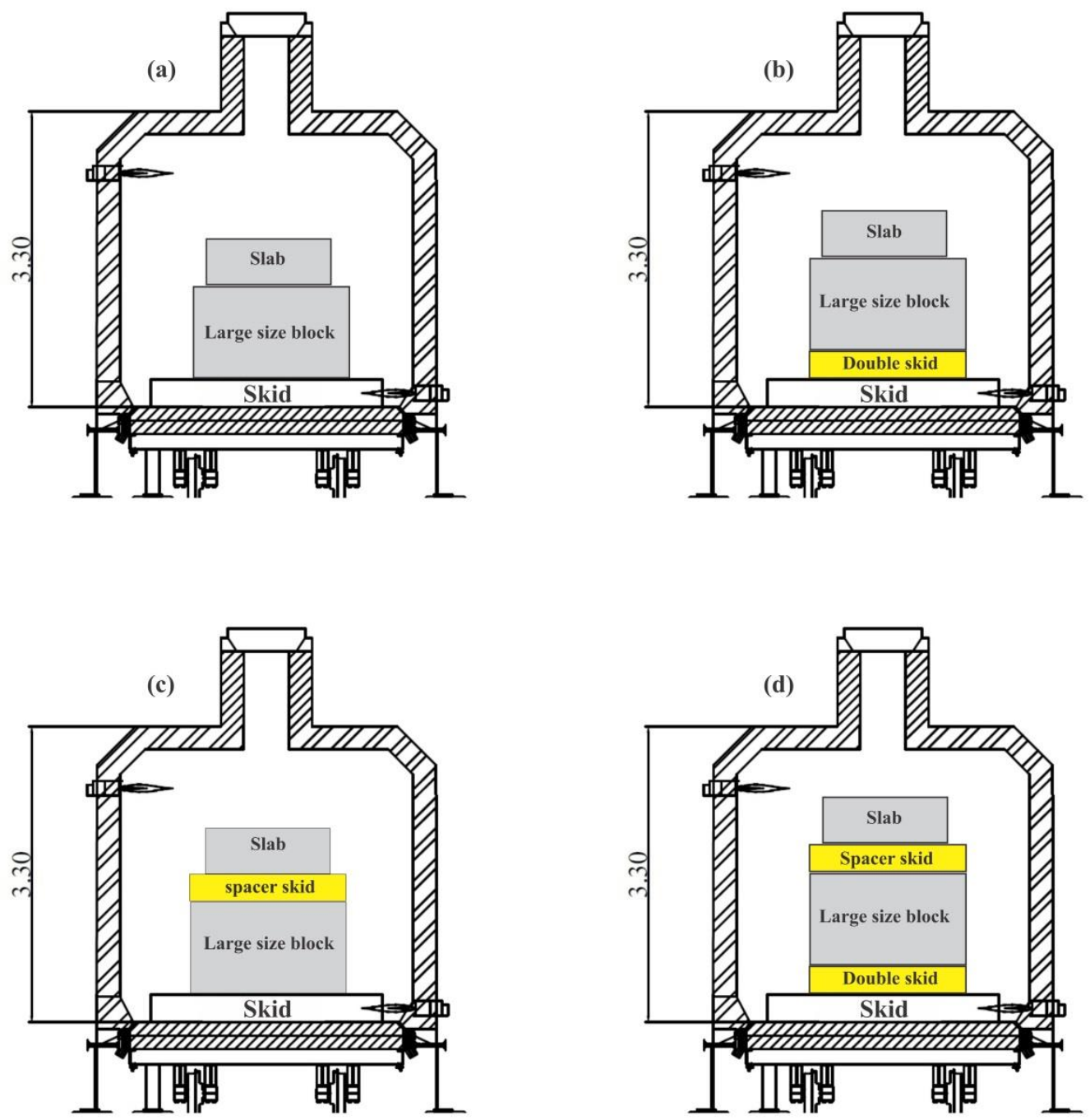

Fig. 1 Four different loading patterns of forgings using skids inside gas-fired heat treatment furnace: a) SK, b) DSK, c) SKC, and d) DSKC. 
A total weight of 130 metric tons, corresponding to the maximum loading capacity of the furnace, was fixed in all the four patterns. Two types of forgings, rectangular parallelepiped shape, called hereafter block and slab, with dimensions of $1.4 \times 0.89 \times 2.72\left(\mathrm{~m}^{3}\right)$ and $1.1 \times 0.5 \times 2.25\left(\mathrm{~m}^{3}\right)$, were used in different configurations. Such loadings were selected to simulate the real practice of the industry for the heat treatment of large size blocks in these heat treatment furnaces. The following denominations were used to characterize each of the four configurations:

SK ${ }^{1}$ : A combination of one block and one slab stacked on its top.

DSK $^{2}$ : The second case study was used to see the effect of double height skids on the temperature non-uniformity.

SKC $^{3}$ : The third case study was aimed to evaluate the effect of spacing skids on the stacking patterns and subsequent uniformity and residence time of blocks in the heat treatment furnaces. Two sizes of spacers with the cross-sectional dimensions of $0.254 \times 0.245 \mathrm{~m}^{2}$ and $0.127 \times 0.127 \mathrm{~m}^{2}$ were used.

DSKC $^{4}$ : A combination of double skids at the bottom and center spacers between the block and the slab was the fourth loading pattern used for the simulations.

\section{Methodology}

\subsection{Computational Details}

\footnotetext{
${ }^{1}$ Single Skid

${ }^{2}$ Double skid

${ }^{3}$ Single skid + Central spacer

${ }^{4}$ Double skid + Central spacer skid
} 
The transient CFD simulations employing a pressure-based solver were carried out using the finite-volume based ANSYS-FLUENT software [42] to solve the Reynolds-averaged NavierStokes (RANS) equations, as follows [42].

$$
\begin{aligned}
& \frac{\partial \rho}{\partial t}+\frac{\partial}{\partial x_{i}}\left(\rho u_{i}\right)=0 \\
& \frac{\partial}{\partial t}\left(\rho u_{i}\right)+\frac{\partial}{\partial x_{j}}\left(\rho u_{i} u_{j}\right)=-\frac{\partial p}{\partial x_{i}}+\frac{\partial \tau_{i j}}{\partial x_{j}}-\frac{\partial}{\partial x_{i}}\left(\rho \overline{u_{i}^{\prime} u_{j}^{\prime}}\right)+F \\
& \frac{\partial}{\partial t}(\rho E)+\frac{\partial}{\partial x_{j}}\left(\rho u_{i} h\right)+\frac{\partial}{\partial x_{j}}\left(u_{i} p\right)=\frac{\partial}{\partial x_{i}}\left(k_{e f f} \frac{\partial T}{\partial x_{i}}-\sum_{z=1}^{n} h_{z} \vec{J}_{z}+u_{i} \tau_{i j}\right)-\frac{\partial}{\partial x_{j}}\left(\overline{\rho u_{i}^{\prime} h_{s}^{\prime}}\right)+q_{s}
\end{aligned}
$$

where, the stress tensor, $\tau_{i j}$, in the above momentum and energy equations (Eqs (2) and (3), respectively) is given by:

$$
\tau_{i j}=\left[\mu\left(\frac{\partial u_{i}}{\partial x_{j}}+\frac{\partial u_{j}}{\partial x_{i}}\right)\right]-\frac{2}{3} \mu \frac{\partial u_{l}}{\partial x_{l}} \delta_{i j}
$$

and the diffusive flux of combustion product species (in Eq (2)) is defined by the Fick's law:

$$
\partial \vec{J}_{z}=-\frac{\mu_{t}}{S c_{k}} \frac{\partial Y_{z}}{\partial x_{i}}
$$

The turbulent combustion and fluid flow were simulated using the standard $k-\varepsilon$ turbulence model [43]. It must be noted that, the above model has already been applied to gas-fired furnaces in several studies $[44,19]$ and approved to be reliable in the context of present study. Due to the high velocity of the combustion products coming from the burner outlet, Arrhenius chemical kinetic calculations were not taken into account and the eddy dissipation model (EDM) [45] was used to simulate the combustion phenomenon. In this model, assuming that the reaction rates are dominated by the turbulence, the species transport formulation (Eq. 6) for the local mass fraction species $\left(\mathrm{Y}_{z}\right)$ is solved (ANSYS, 2016). 


$$
\frac{\partial}{\partial t}\left(\rho Y_{z}\right)+\nabla \cdot\left(\rho \bar{v} Y_{z}\right)=-\nabla \cdot \overline{J_{z}}+\dot{R}_{z}+\dot{S}_{z}
$$

where, $\dot{R}_{z}$ represents the net production rate of the $\mathrm{z}_{\text {th }}$ component.

The unsteady SIMPLE algorithm [46] was applied for pressure-velocity coupling in a computational domain including 15,155,000 hexahedral non-uniform grids, as depicted in Fig. 2 .

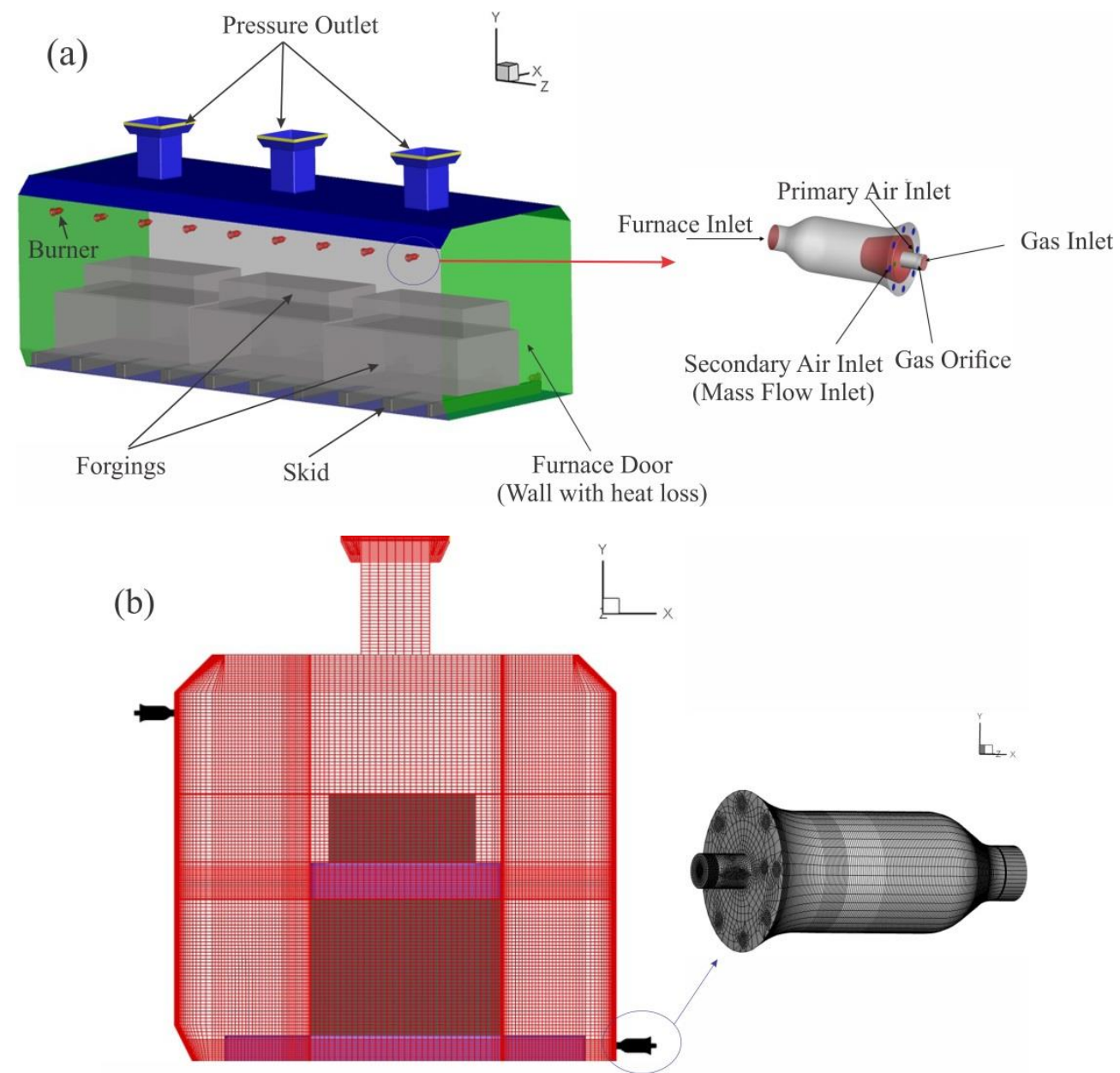

Fig. 2 Computational domain, including: (a) boundary conditions of SK case study, and (b) computational grids in SKC loading pattern.

Finer cells with low growth rate were used near the burners to resolve significant variations of the complex flow in this region (in the range of high temperature and species concentration gradient). The grid size includes $6,408,000$ non-uniform cells in the burner domains $(356,000$ cells in each burner). Grid independency tests were performed using two other meshes including 10597900 and 
19712100 cells. The difference between results of the mesh with 15155000 and the fine mesh were negligible. Therefore, the medium mesh with 15155000 cells was used in the simulations. Further details of the simulations procedure and boundary conditions specifications were discussed by Arkhazloo et al. [30]. The discrete ordinates model DO [47] using the weighted-sum-of-gray gases model (WSGGM) of Smith et al. [48] was also employed to solve the radiative transfer equation (RTE) considering the absorption and emission effects of the furnace medium.

\subsection{Forgings Temperature Measurements}

This part of experimentations includes temperature measurements at the surface of the forgings in the gas-fired heat treatment furnace. Measurements was conducted in a gas-fired furnace at Finkl Steel-Sorel [49]. The furnace with three relatively similar zones was loaded with a total weight 130 tons. Six K type thermocouples were embedded in different locations of the parts in the central zone of the furnace. Details regarding other characteristics of the furnace and the methods developed for reliable installation and temperature reading are provided in a recent publication by Arkhazloo et al. [30].

\subsection{Hybrid Approach}

A hybrid methodology combining the CFD simulation results and experimental dilatometer tests was used to determine the minimum heat treatment time that is required to achieve the desired mechanical properties. Specifically, the transient temperature histories of the hottest and coldest regions of the parts were first predicted by the developed CFD model. These two points were then used as the critical points to evaluate and optimize the isothermal stage of the heat treatment cycle. This methodology includes laboratory physical simulations of the tempering cycle during the isothermal and non-isothermal tempering (acquired through the CFD simulation) and subsequent 
hardness measurements of the steel for the critical points. Considering that hardness is the most widely used criteria in industry for qualifying a successful heat treatment process; therefore, hardness was selected as the target mechanical property for evaluation of the heat treatment process and subsequent residence time optimization in this study.

The hybrid methodology process was started with finding the hardness of samples after applying non-isothermal tempering history of the critical points. Then several isothermal tempering were carried out to find an equivalent isothermal tempering times leading to the measured hardness in step one and desired hardness at the end of the tempering process. The difference between these two times was considered as the optimum holding time in the isothermal part of the tempering process.

The chemical composition of the investigated high-strength low-alloy steel is provided in Table 1. Cylindrical samples $10 \mathrm{~mm}$ in length and $4 \mathrm{~mm}$ in diameter were cut from near the surface and central zones of the slab, which had underwent open-die forging at around $1260^{\circ} \mathrm{C}$.

Table 1 Chemical analysis of the investigated steel - Wt. \% [49]

\begin{tabular}{|c|c|c|c|c|c|c|}
\hline Mn & Si & Mo & Cr & Ni & C & Other \\
\hline 0.85 & 0.4 & 0.45 & 1.85 & 0.47 & 0.35 & Micro alloying \\
\hline
\end{tabular}

The initial tempering process of the present slabs with dimensions of $1.1 \times 0.5 \times 2.25 \mathrm{~m}^{3}$ was around 60 hours to achieve a nominal final hardness between 31-34 HRC (in the case of multiple loading). This heat treatment cycle includes a nominal 24 hours of heating stage up to $855 \mathrm{~K}$ (non-isothermal tempering) and 38 hours of holding at this temperature (isothermal tempering). All the heat treatment cycles applied to the parts in the furnace were physically simulated using the highresolution TA DIL 805A/D dilatometer machine (TA instruments, New Castle, DE, USA) [50]. 
The heating rates using the validated CFD results were adjusted to simulate that of actual heating cycle of forgings during non-isothermal tempering. A prior austenitization process (including heating up to $870^{\circ} \mathrm{C}$, followed by 10 minutes holding at this temperature for homogenization) and subsequent cooling rate of $3^{\circ} \mathrm{C}$ to produce a martensitic microstructure resembling the expected microstructure on the surface of an actual forging after water quenching (i.e., before starting the tempering process in the heat treatment furnace) was considered for the sample preparations. Dilatometry tested samples were then cut along their longitudinal axis and then polished according to standard metallography preparation methods. Finally, Rockwell C hardness measurements were made according to ASTM E18-19 on the polished surfaces to determine the impact of the heat treatment conditions on mechanical properties. A minimum of 25 measurements with a load of $1 \mathrm{Kg}$ and a dwell time of 10 s were used.

\section{Results and Discussion}

\subsection{Validation}

Comparison between the present numerical prediction and the experimental measurement of transient temperature of the ingot at the centre of the large block's right surface (surface facing the lower burners) in the SK configuration is represented in Fig. 3. Although a slight over-prediction (maximum value of 3\%) can be observed, the validity of the CFD model is therefore confirmed and further investigations could be carried. 


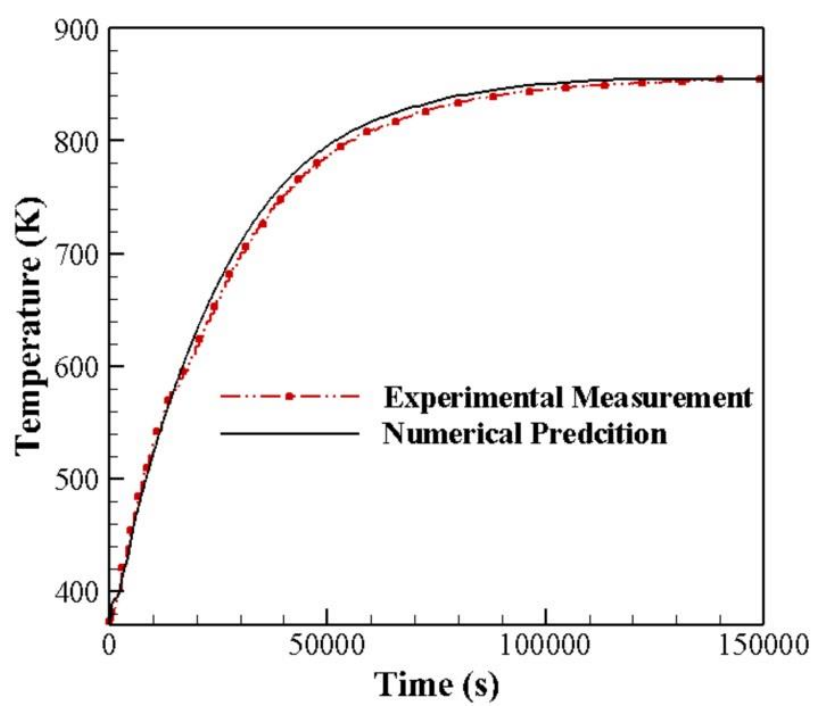

Fig. 3 Validation of CFD simulations in multiple loading configurations.

\subsection{Loading Pattern Analysis}

Temperature evolutions of different locations of the block and the slab in the conventional SK loading pattern (first case study) are shown in Fig. 4.

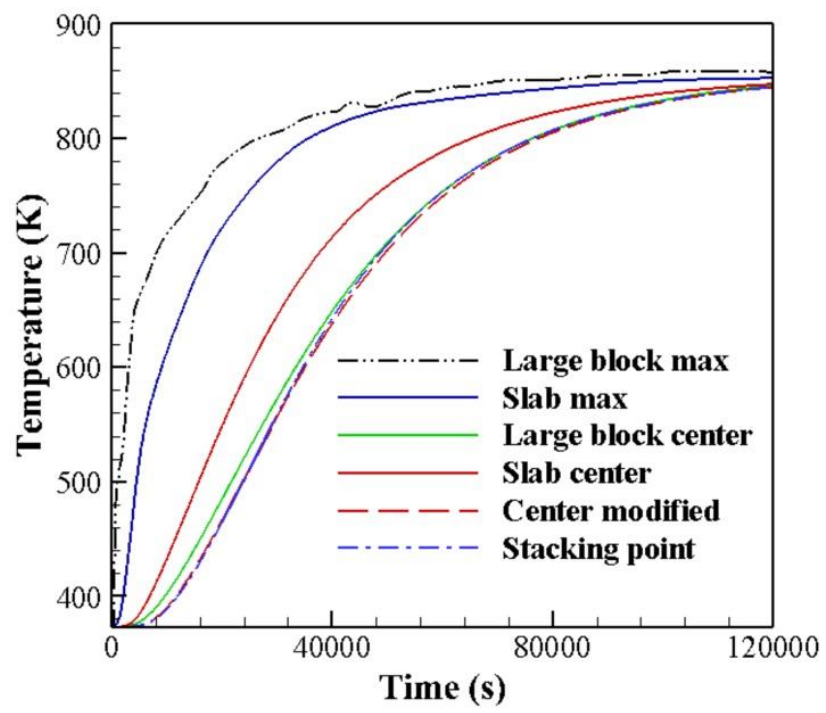

Fig. 4 Temperature evoutions of forgings in conventional SK loading pattern.

There is a considerable temperature difference between the forging's maximum temperature and their corresponding interface, hereafter called stacking point. This point which is actually at the surface of the block is heated after the center of the block. The difference is also observed for the 
slab where the stacking point at the surface of the slab has noticeably lower temperatures in comparison with the center of the block (on the contrary to the expectation of a regular heat treatment from surface to center). In this figure center modified represents the minimum temperature of the whole loadings during the heat treatment (i.e., center of the whole geometry).

Fig. 5 illustrates transient histories of maximum temperature difference (i.e., maximum non-uniformity) of the block and slab surfaces for the four different loading patterns.
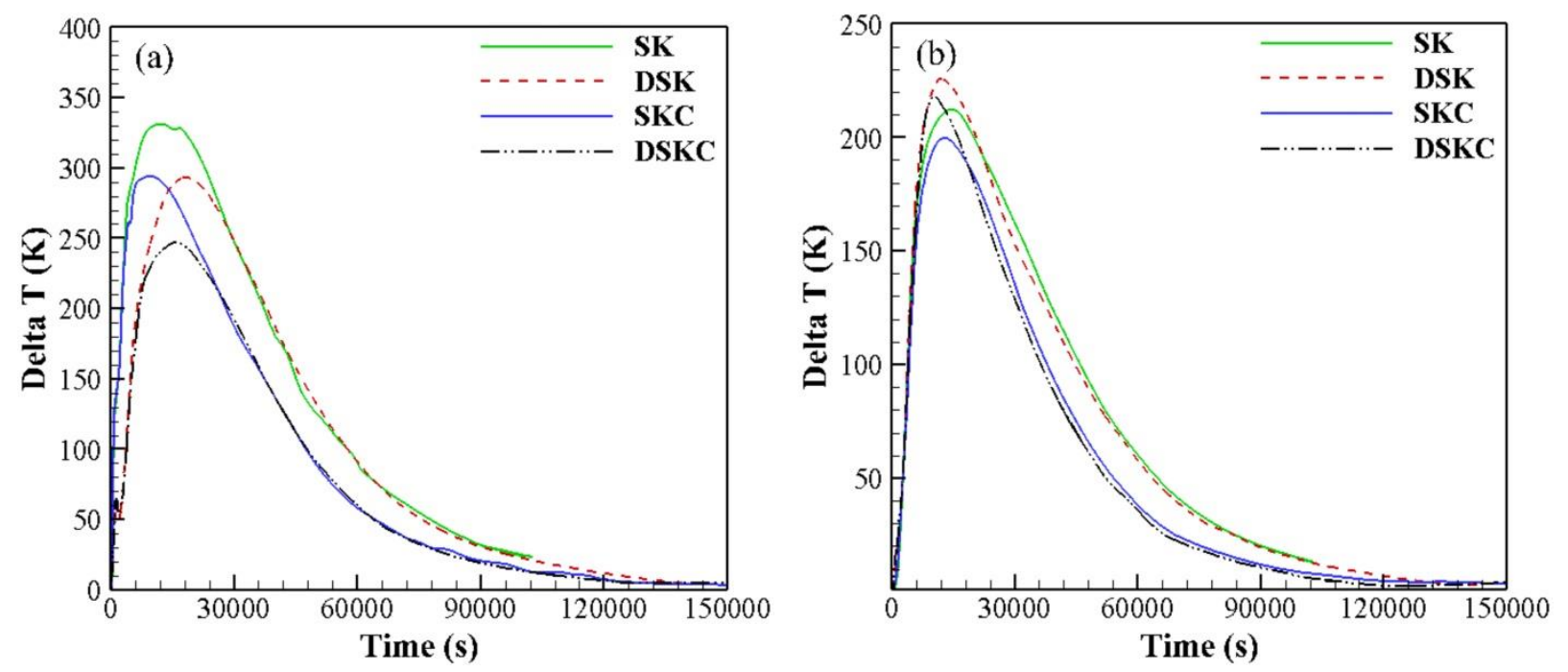

Fig. 5 Comparison of maximum identified non-uniformities for different loading patterns: a) size block and, b) slab.

Besides, in Fig. 5 the area under each curve represents the total non-uniformity of the blocks during the heat treatment. Therefore, the differences from one case to another would be representing the difference in total non-uniformities. Fig. 5 also shows that shrinkage of the total non-uniformity (area under each curve) was clearly affected when skids and spacers were used. As shown in Table 2, the combination of double-height skids and central spacers in DSKC could lower the temperature non-uniformity of the block up to $31 \%$, which is a very significant gain. The effects of spacers and double-height skids are also interpreted by using Fig. 5 and Table 2. The SKC case study giving a reduction in the temperature non-uniformity of almost $21 \%$, as compared with the 
$12 \%$ of DSK, demonstrates a higher effectiveness of the central spacers in reducing temperature non-uniformities.

Fig. $5 \mathrm{~b}$ and Table 2 , summarize the trends observed for the slab. Specifically, the maximum non-uniformity and total non-uniformity for the SKC case study were reduced by $7 \%$ and $18 \%$, respectively. However, in contrast to the block, under the DSK configuration the maximum and total temperature non-uniformity increased compare to the SK configuration. It is also interesting to know that for the DSKC case, while approximately the same reduction in the total nonuniformity was observed; however, the maximum temperature non-uniformity (pack of the curve) of the slab slightly increased by $2.6 \%$. This reverse effect could be related to the fact that the spacers in this case study increased the treatment height, reduced the distance between the upper surface of the slab and the up burners leading to a higher temperature at this surface (see Fig. 6).

Table 2 Total temperature non-uniformity reduction of forgings for different loading patterns in comparison with conventional SK loading.

\begin{tabular}{|cccc|}
\hline Forgings & DSK & SKC & DSKC \\
\hline Block & $12 \%$ & $21 \%$ & $32 \%$ \\
\hline Slab & $-1 \%$ & $18 \%$ & $19 \%$ \\
\hline
\end{tabular}

Contours of the temperature distributions in the central cross-section of the forging blocks for the four different loading patterns, $t=t_{\mathrm{T}} / 6$, are represented in Fig. 6 . These are for when the maximum temperature non-uniformity occurred in the SK case study (see Fig. 5). It can be seen that in the SK configuration considerable irregular temperature non-uniformities existed in the blocks from one end to another. The cross-section of the forged block encompasses three high temperature regions facing with the down burners and very cold region at the upper surface where the slab was positioned on the top of the block. This shows the importance of products' relative 
locations with respect to other products and furnace equipment. The influence of furnace details (such as burner positions, skids, and loading relative locations) on the heat treatment pattern of large size blocks within the gas-fired furnace was discussed in a recent paper by Arkhazloo et al. [30]. As shown in Fig. 6a, the coldest part of the block in the conventional SK case study is not at the center of the block and, on the contrary to the general expectation, it occurs in the upper quarter of the block near the upper face (see also the curve of center modified in Fig. 4). This unusual trend could be explained by considering that in the SK pattern, due to lack of effective active surfaces in the stacking zone, the whole configuration was heated quite similar to a single body and the coldest point of the loading is close to the center of the corresponding body mass. In other words, due to the lack of active surfaces participating in the heat transfer phenomenon in the stacking zone, the critical thickness of the blocks was substituted by the thickness of the total loading mass, and the coldest point was occurred near the center of this new equivalent critical thickness. The same behavior can be seen for the slab where the minimum temperature occurs near the bottom surface (the nearest surface to the coldest point of total loading) rather than at the center of the block. This finding is of significant impact from a practical point of view for the steel industry. That is, that part loading configurations need to be taken into account as they could introduce important temperature non-uniformities, and hence, non-uniform properties through the volume of the part even though the total heat-treated mass is identical. 

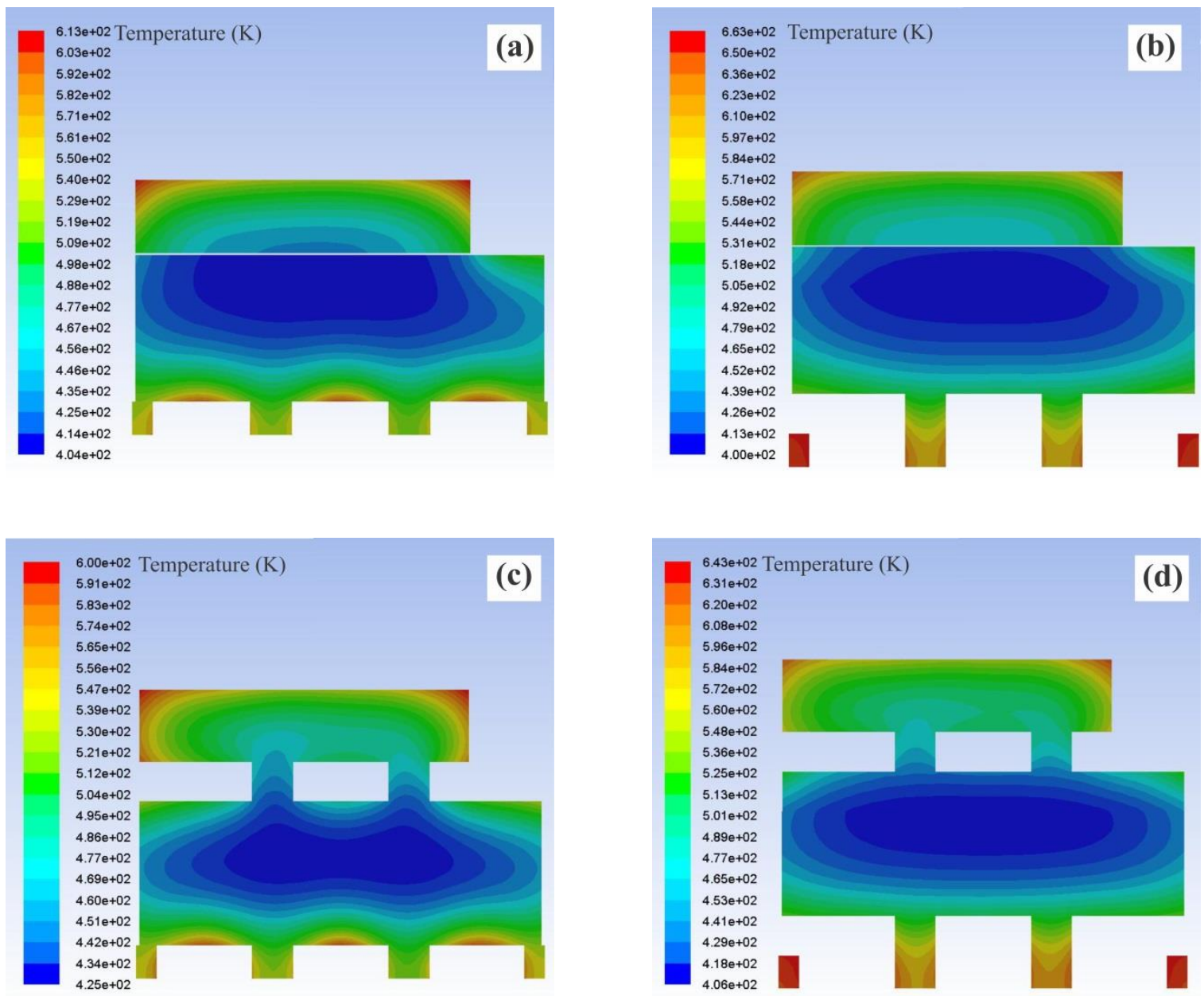

Fig. 6 Contours of temperature distribution in central cross sections of forgings for four different loading patterns at $\boldsymbol{t}=\boldsymbol{t}_{\boldsymbol{T}} / \mathbf{6}:$ a) SK, b) DSK, c) SKC, and d) DSKC.

Analysis of the results reported in Fig. 6c, d, demonstrate that the use of central spacing's between the forgings in the SKC and DSKC increased the temperature of the upper surface of the block and the lower surface of the slab. The central spacers could effectively retrieve these surfaces to absorb radiation and convection heat fluxes from the furnace heating chamber leading to identified temperature increases. In other words, central spacers increasing the surface to volume ratios on the loading could effectively contribute to the desired temperature distribution of the blocks. This resulted in $21 \%$ reduction in temperature non-uniformity for the case of SKC in comparison to the conventional SK loading pattern. The results also show that when double height skids were used 
(Fig. 6b and d), the high temperature zones located in the lower part of the block were eliminated, resulting in a $12 \%$ reduction in temperature non-uniformity in the case of DSK and a total drop of $31 \%$ when double height skids alongside central spacers were used (Fig. 6d). However, the doubleheight skids could not affect the temperature uniformity of slabs and these blocks are mainly affected by the central spacers.

\subsubsection{Influence of spacer skids size on heat transfer modes}

The above results clearly demonstrated that the inclusion of the spacers in the analysis affected the severity and distribution of temperature non-uniformity. Although, convection and radiation are the two most important heat transfer mechanisms during the heat treatment process of forgings [1], both from fundamental and application points of view, it is however important to quantify the role of each mode in the presence of spacers. To this end, two different spacers with the cross-sectional areas of $0.254 \times 0.245 \mathrm{~m}^{2}(\mathrm{SKC})$ and $0.127 \times 0.127 \mathrm{~m}^{2}$, half-size SKC or SKHC, were considered for the thermal analysis and the results are reported in Fig. 7a-d.
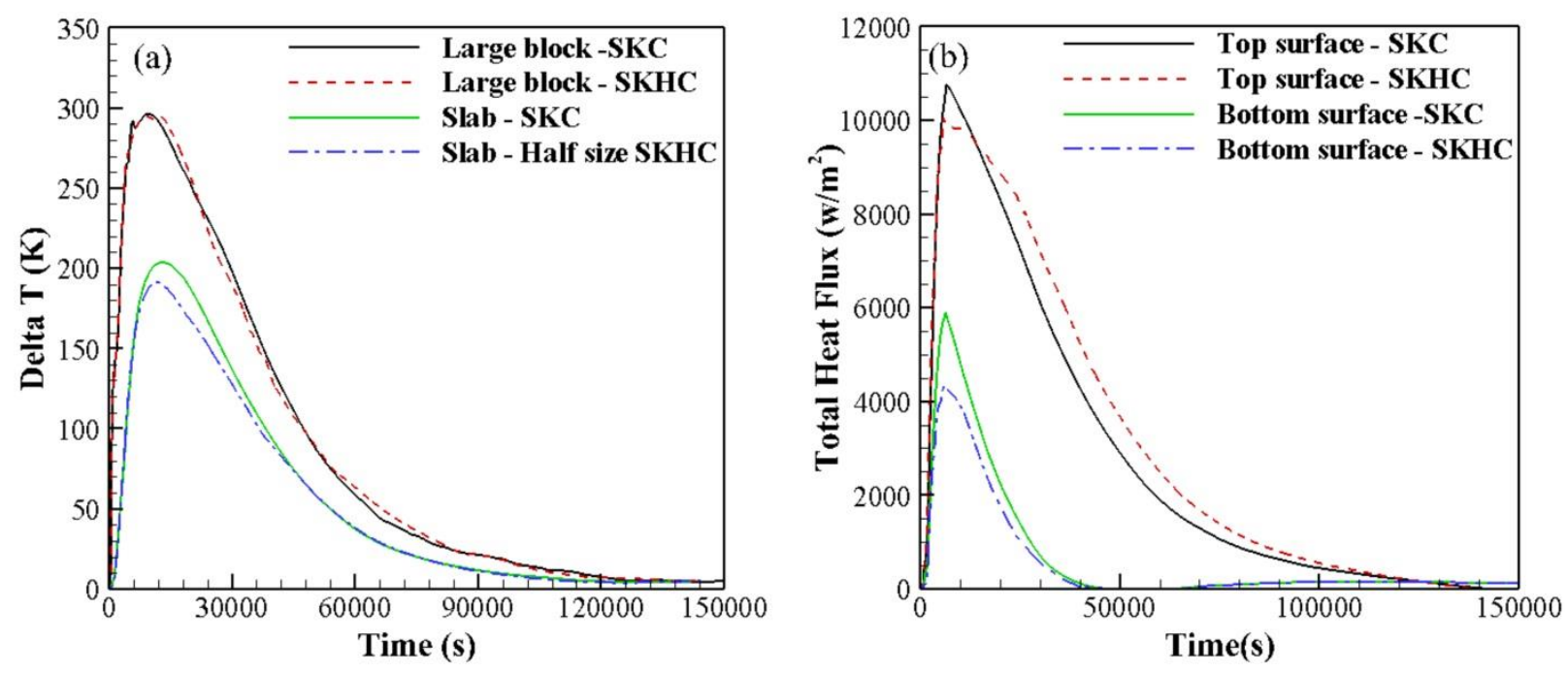

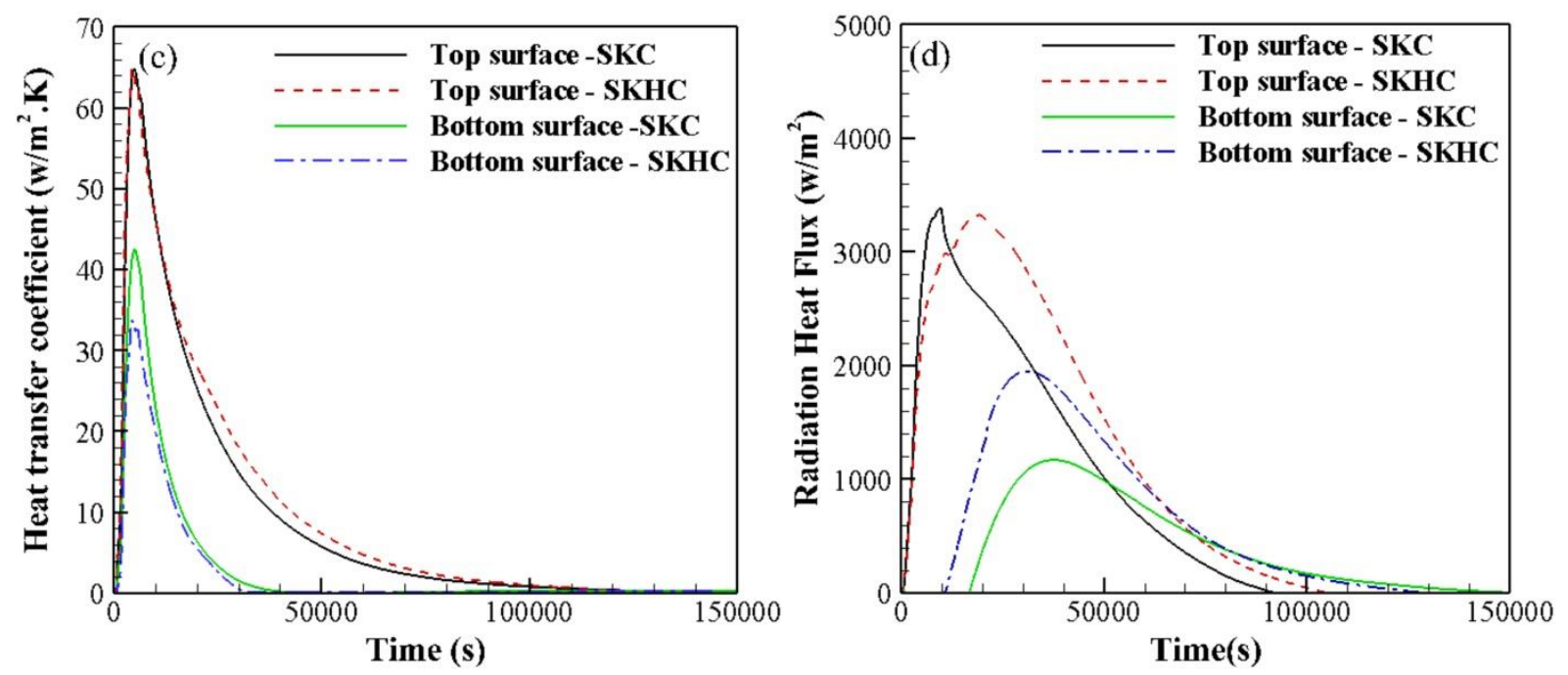

Fig. 7 Transient history of a) maximum non-uniformity of forgings, b) total heat flux, c) convection heat transfer coefficient and, d) radiation heat flux on forgings surfaces with two different sizes of spacer skids.

Fig. 7 shows that the reason for the ascending/descending trend of temperature non-uniformities could be traced using the transient trend of heat fluxes to the block surfaces. It can be seen that the maximum temperature differences occurred in the first part of the process when the furnace tends to reach the pre-defined temperature and the heat fluxes to the surfaces have ascending trend. Iinterestingly despite doubling the height and the width of the spacers, the total temperature non-uniformity decreased by the same amount (about $21 \%$ ). In Fig. 7b, the total heat fluxes are compared for the two conditions. The convection heat transfer coefficients were calculated for both cases, and as reported in Fig. 7c, the values are quite similar while the radiation heat fluxes are different (Fig. 7d). This could be explained in terms of the differences in radiation view factors of the surfaces for these two different spacer sizes. Taking in to account the approximately similar total heat flux and the same temperature non-uniformity distribution, it can be said that the spacers affect mainly the convection heat transfer mode and therefore the 
temperature distribution uniformity is controlled by a convection-based mechanism rather than a radiation one.

\subsubsection{Influence of loading patterns on the non-isothermal tempering residence time}

The evolution of transient average temperature of the forgings and derivation of temperature with respect to time (heating rate) for the different loading patterns are presented in Fig. 8.
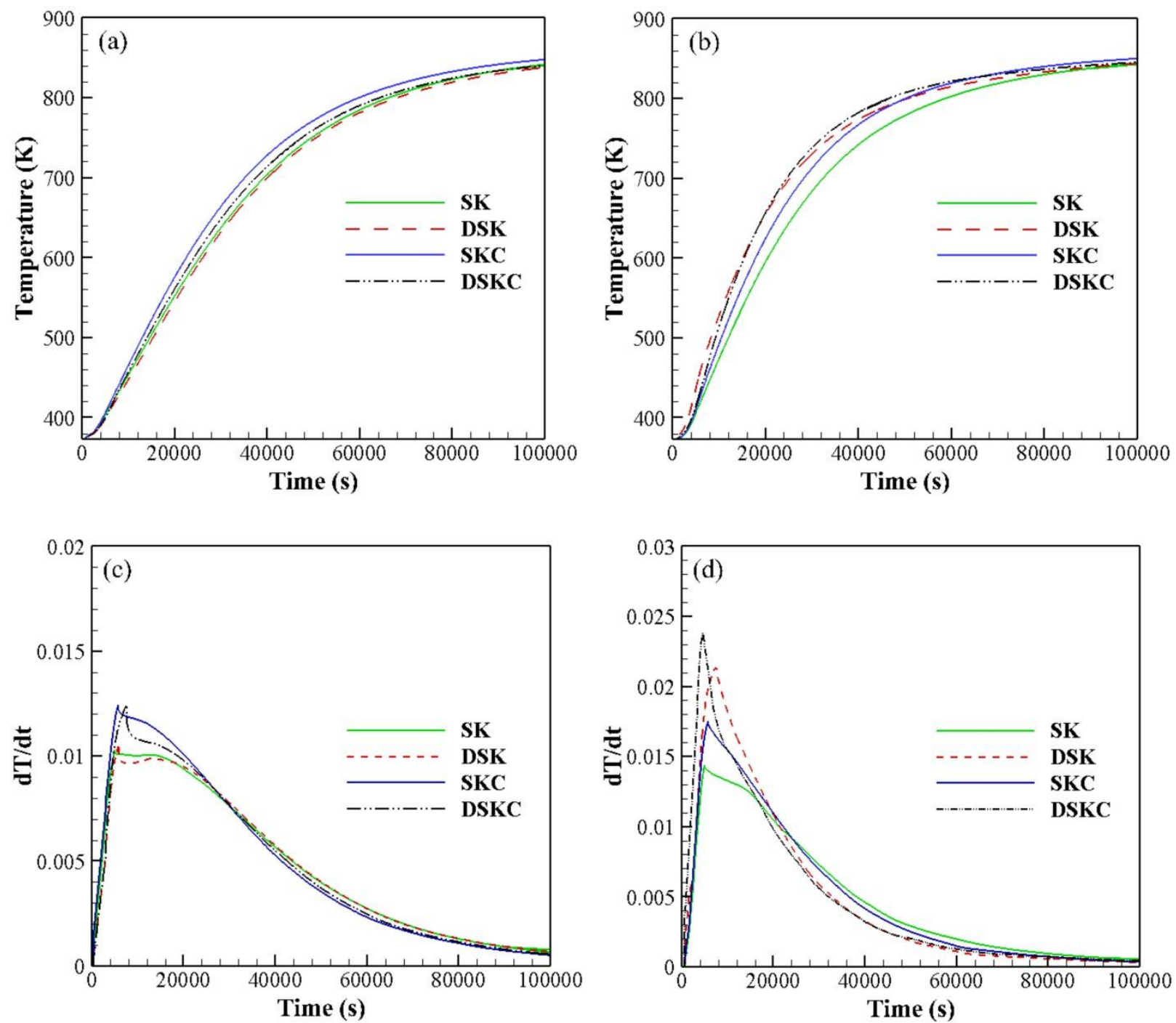

Fig. 8 Forgings average temperature evolution: a) block, b) slab and derivative of temperature evoloution with respect to time c) block, and d) slab in different loading pattrens. 
It can be seen that positioning of skids and spacers inside the furnace and between the blocks could affect the average transient temperature evolution of the forgings (Fig. 8a, b) as well as their experienced heating rates in the non-isothermal part of the tempering process (Fig. 8c, d). It resulted in faster heating rates for both blocks in the SKC and DSKC configurations in comparison with the conventional SK case study leading to higher transient temperature experienced by the blocks (Fig. 8a, b). Specifically, the slab is more affected by the central spacer skids usage (see also Table 3). This could be illustrated by the surface to volume ratio of the slab compared to the large size block as the central spacers retrieved similar surfaces for both blocks on the stacking zone of the SK loading. Therefore, the slab with a higher surface to volume ratio change, is more affected by the central spacers. However, the DSK method resulted in slightly lower heating rates for the block (Fig. 8c) and subsequently lower temperatures (Fig. 8a) because it increased the distance between the block and lower active burners. It should be noticed that although doubling the size of the skid did not reduce the non-uniformity of the slab effectively (see Fig. 5b); however, it increased the total height and therefore augmented the contribution of the upper burners to the heating process. This leads to higher heating rates under the DSK and DSKC conditions (Fig. 8d).

The relative time reduction (in the heating stage) to reach the target temperature for different loading patterns in comparison with the conventional SK loading is presented in Table 3. Results indicated that the DSKC configuration could reduce the heat treatment process by 0.5 hours for the block and 3 hours for the slab. Besides, the SKC configuration could reduce the process time by 2.5 hours and 3.5 hours for the block and the slab, respectively. Therefore, the SKC loading pattern is more effective to reduce the non-isothermal tempering residence time of the blocks, while, the DSKC pattern is more effective with the view to obtain more homogenous temperature distribution within the block (See Fig. 5a and Table 2). 
Table 3 Residence time reduction of forgings at different loading patterns in comparison with conventional SK loading pattern.

\begin{tabular}{|cccc|}
\hline Forgings & DSK & SKC & DSKC \\
\hline Block & $-1(\mathrm{~h})$ & $2.5(\mathrm{~h})$ & $0.5(\mathrm{~h})$ \\
\hline Slab & $0.5(\mathrm{~h})$ & $3.5(\mathrm{~h})$ & $3(\mathrm{~h})$ \\
\hline
\end{tabular}

\subsection{Residence time improvement of forgings during isothermal tempering process}

The heat treatment process consists of a non-isothermal heating (i.e., the time to reach the target temperature in the loaded furnace) and an isothermal part (i.e., holding at the target temperature for a specified time). As shown in Table 3, the effective usage of skids and spacers could reduce the heating time (i.e., the non-isothermal heating step) by about $10 \%$ and $14.5 \%$ in comparison with the conventional SK non-isothermal tempering for block and slab, respectively. This would mean that the isothermal part could be reduced without affecting the final properties. To do so the hybrid methodology was used to reduce the unnecessary holding time of forgings inside the gasfired heat treatment furnace. According to the simulations results the hottest and coldest points at the surface of the slab in the SKC case study reaches the target temperature of $582^{\circ} \mathrm{C}(855 \mathrm{~K})$ after 24.5 and 31 hours, respectively (i.e., 6.5 hours of extra isothermal treatment for the hottest point). The dilatometer experiments were carried out with the two above non-isothermal heating times and the material hardness (Rockwell C scale, HRC) values were determined. The initial hardness of $54 \mathrm{HRC}$ (after austenitizing and quenching) was reduced to $37.5 \pm 0.1 \mathrm{HRC}$ and $37.4 \pm 0.1 \mathrm{HRC}$ for 24.5 and 31 hours of non-isothermal tempering, respectively. Thus, an isothermal tempering should be designed to reduce these hardness values to the final desired 34 HRC (within the acceptable range of 31-37 HRC). 
Fig. 9 represents the detail of the conducted isothermal tempering cycles and their relevant acquired hardness. 20 hours and 46 hours of isothermal tempering at $582^{\circ} \mathrm{C}$ resulted in $37.6 \pm 0.1$ HRC (equivalent to the hottest point hardness after the non-isothermal tempering) and $34.1 \pm 0.1$ HRC (desired hardness after the tempering process), respectively. Therefore, the present results indicated that a total time of 50.5 hours including 24.5 hours of non-isothermal and 26 hours (equal to the subtraction of 20 from 46 hours) of isothermal holding was needed to reach the target hardness value of $34 \mathrm{HRC}$.

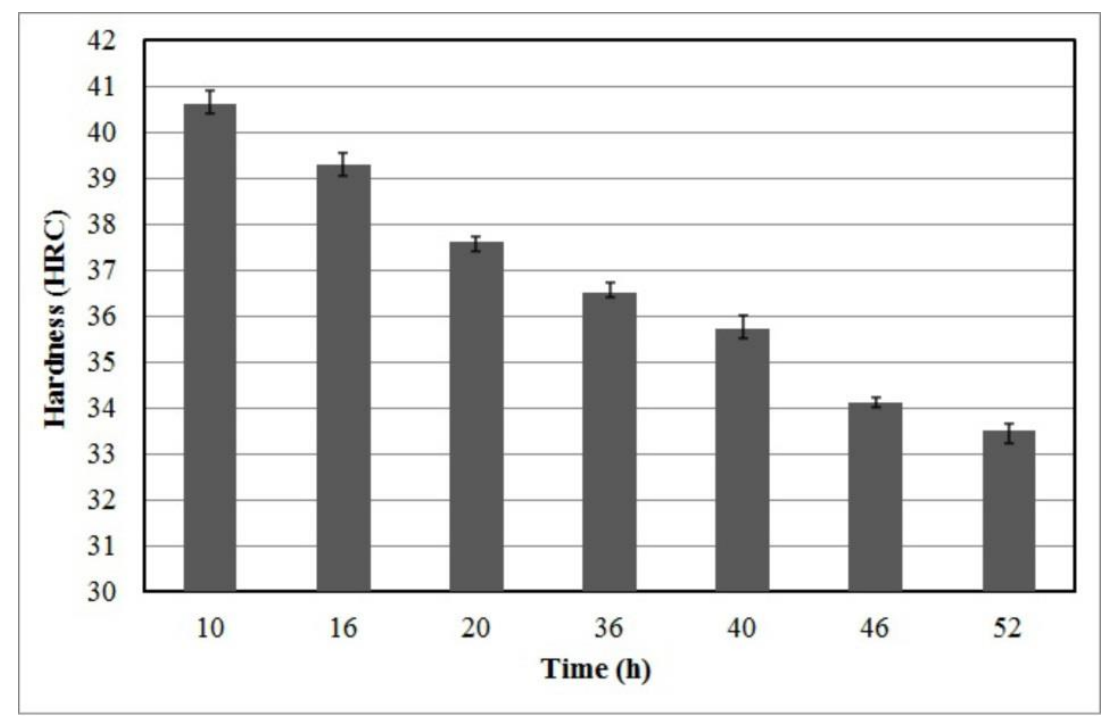

Fig. 9 Hardness measurements after isothermal tempering at $582^{\circ} \mathrm{C}$ for different holding times. The proposed hybrid approach was validated by using two other tests where the proposed heating cycle was examined for the slab hottest and coldest points. In these experiments, the nonisothermal heating cycle taken from the CFD results followed by the optimal calculated isothermal tempering, resulted in $33.9 \pm 0.1$ and $34.6 \pm 0.1 \mathrm{HRC}$ hardness values which are in the acceptable range for this product.

On the basis of the obtained results, the total residence time of the parts inside the heat treatment furnace could be reduced by 9.5 hours (i.e., $15.5 \%$ reduction). Considering the excessive 
energy consumption of this type of furnaces and the very large number of the heat-treated parts, such a time saving along with improving the temperature uniformity; and hence, properties of the final product could significantly contribute to the production cycle from both cost and quality points of view.

\section{Conclusions}

The loading pattern effect on the forging's temperature uniformity and their residence time inside the gas-fired heat treatment furnaces was investigated using the CFD simulation and experimental temperature measurements. Besides, a hybrid numerical-physical simulation approach was introduced and performed to optimize the residence time of forgings inside gas-fired heat treatment furnaces. The following conclusions can be drawn from the present work:

1) Forgings in the non-optimized conventional loading pattern experienced temperature nonuniformities up to $331 \mathrm{~K}$ due to furnace geometry and loading pattern.

2) Using double size skids and central spacers reduced the temperature non-uniformity of forgings inside the gas-fired furnace up to $32 \%$.

3) The thermal analysis of loading configurations proved that the convection heat transfer was the dominant mechanism in the presence of central spacers to affect the temperature uniformity of the heavy steel parts.

4) It was possible to reduce the total residence time of slabs (including non-isothermal and isothermal tempering) by about $15.5 \%$ in the gas-fired heat treatment furnace.

5) A hybrid methodology was proposed and validated for residence time optimization of forging. The proposed approach could be applied to other furnace types or part geometries. 


\section{Declarations}

Funding: This work was supported by the MITACS in the framework of [IT03151] Grant. Conflicts of interest/Competing interests: The authors declare that they have no known competing financial interests or personal relationships that could have appeared to influence the work reported in this paper.

Availability of data and material: Not applicable

Code availability: ANSYS-FLUENT software

\section{Acknowledgement}

The authors are very grateful to Finkl Steel, especially the R \& D, Metallurgy and Engineering Departments, for providing the real-scale instrumentation and measurements used in the present research.

\section{References}

1. Totten GE (2006) Steel heat treatment: metallurgy and technologies. CRC press, Portland, Oregon, U.S.A.

2. Kang J, Rong Y (2006) Modeling and simulation of load heating in heat treatment furnaces. J Mater Process Technol 174 (1-3):109-114. https://doi.org/10.1016/ j.jmatprotec.2005.03.037 3. Janjušević Z, Gulišija Z, Mihailović M, Patarić A (2009) The investigation of applicability of the Hollomon-Jaffe equation on tempering the HSLA steel. CICEQ 15 (3):131-136. https://doi.org/10.2298/CICEQ0903131J

4. Gao M, Reid C, Jahedi M, Li Y (2000) Estimating equilibration times and heating/cooling rates in heat treatment of workpieces with arbitrary geometry. J Mater Eng Perform 9 (1):62-71. https://doi.org/10.1361/105994900770346295 
5. Hao X, Gu J, Chen N, Zhang W, Zuo X (2008) 3-D Numerical analysis on heating process of loads within vacuum heat treatment furnace. Appl Therm Eng 28 (14-15):1925-1931. https://doi.org/10.1016/j.applthermaleng.2007.12.007

6. Korad T, Ponboon M, Chumchery N, Pearce JT (2013) Overview of Flow Analysis Simulation in Improving Heat Treatment Conditions. Chiang Mai J Sci 40 (5):898-908

7. Cheng L, Brakman C, Korevaar B, Mittemeijer E (1988) The tempering of iron-carbon martensite; dilatometric and calorimetric analysis. Metall Trans A 19 (10):2415-2426. https://doi.org/10.1007/BF02645469

8. Ding W, Liu Y, Xie J, Sun L, Liu T, Yuan F, Pan J (2019) Effect of Carbide Precipitation on the Evolution of Residual Stress during Tempering. Metals 9 (6):709 https://doi.org/10.3390/met9060709

9. Kekana N, Shongwe MB, Johnson OT, Babalola BJ (2019) Densification behaviour and the effect of heat treatment on microstructure, and mechanical properties of sintered nickel-based alloys. Int J Adv Manuf Technol 103 (5-8):2227-2233. https://doi.org/10.1007/s00170-01903698-y

10. Bakhsheshi-Rad HR, Monshi A, Monajatizadeh H, Idris MH, Kadir MRA, Jafari H (2011) Effect of multi-step tempering on retained austenite and mechanical properties of low alloy steel. J Iron Steel Res Int18 (12):49-56. https://doi.org/10.1016/S1006-706X(12)60009-0

11. Yu N, Yang Y, Jourdain R, Gourma M, Bennett A, Fang F (2020) Design and optimization of plasma jet nozzles based on computational fluid dynamics. Int J Adv Manuf Technol 1-10. https://doi.org/10.1007/s00170-020-05568-4 
12. Palacio-Caro ID, Alvarado-Torres PN, Cardona-Sepúlveda LF (2020) Numerical simulation of the flow and heat transfer in an electric steel tempering furnace. Energies 13 (14):3655. https://doi.org/10.3390/en13143655

13. García AM, Colorado AF, Obando JE, Arrieta CE, Amell AA (2019) Effect of the burner position on an austenitizing process in a walking-beam type reheating furnace. Appl Therm Eng 153:633-645. https://doi.org/10.1016/j.applthermaleng.2019.02.116

14. Li H, Zhao Y, Ji Y, Xue S, Liu Y (2020) Numerical Study on Temperature Uniformity of Regenerative Heating Furnace. In: IOP Conference Series: Mater Sci Eng. vol 1. IOP Pub, p 012058. https://doi.org/10.1088/1757-899X/721/1/012058

15. Tzeng S-J, Chen X-X, Wang W-C (2020) Numerical studies of metal particle behaviors inside the selective laser melting (SLM) chamber through computational fluid dynamics (CFD). Int J Adv Manuf Technol 107 (11-12):4677-4686, https://doi.org/10.1007/s00170-020-05351-5 16. Wang J, Gu J, Shan X, Hao X, Chen N, Zhang W (2008) Numerical simulation of high pressure gas quenching of H13 steel. J Mater Process Technol 202 (1-3):188-194. https://doi.org/10.1016/j.jmatprotec.2007.08.059 17. Cosentino F, Warnken N, Gebelin J-C, Reed RC (2013) Numerical and experimental study of post-heat treatment gas quenching and its impact on microstructure and creep in CMSX-10 superalloy. J Mater Process Technol 213 (12):2350-2360. https://doi.org/10.1016/j.jmatprotec.2013.06.025 18. Harish J, Dutta P (2005) Heat transfer analysis of pusher type reheat furnace. Ironmaking \& steelmaking 32 (2):151-158. https://doi.org/10.1016/j.jmatprotec.2013.06.025 
19. Liu Y, Li J, Misra R, Wang Z, Wang G (2016) A numerical analysis of slab heating characteristics in a rolling type reheating furnace with pulse combustion. Appl Therm Eng 107:1304-1312. https://doi.org/10.1016/j.applthermaleng.2016.07.074

20. Mayr B, Prieler R, Demuth M, Moderer L, Hochenauer C (2017) CFD analysis of a pusher type reheating furnace and the billet heating characteristic. Appl Therm Eng 115:986-994. https://doi.org/10.1016/j.applthermaleng.2017.01.028

21. Tang G, Wu B, Bai D, Wang Y, Bodnar R, Zhou CQ (2017) Modeling of the slab heating process in a walking beam reheating furnace for process optimization. Int J Heat Mass Transfer 113:1142-1151. https://doi.org/10.1016/j.ijheatmasstransfer.2017.06.026

22. Lin C-N, Luo Y-P, Jang J-Y, Wang C-H (2018) Novel Approach to Estimate the Optimum Zone Fuel Mass Flow Rates for a Walking Beam Type Reheating Furnace. Heat Transfer Eng 39 (7-8):586-597. https://doi.org/10.1080/01457632.2017.1325656

23. Gur CH, Pan J (2008) Handbook of thermal process modeling steels. CRC Press, Boka Raton, FL, USA.

24. Yang Y, De Jong RA, Reuter MA (2007) CFD prediction for the performance of a heat treatment furnace. Prog Comput Fluid Dyn 7 (2):209.https://doi.org/10.1504/PCFD.2007.013013 25. Schluckner C, Gaber C, Demuth M, Forstinger S, Prieler R, Hochenauer C (2018) CFDmodel to predict the local and time-dependent scale formation of steels in air-and oxygen enriched combustion atmospheres. Appl Therm Eng 143:822-835. https://doi.org/10.1016/j.applthermaleng.2018.08.010 26. Prieler R, Mayr B, Demuth M, Spoljaric D, Hochenauer C (2015) Application of the steady flamelet model on a lab-scale and an industrial furnace for different oxygen concentrations. Energy 91:451-464. https://doi.org/10.1016/j.energy.2015.08.070 
27. Mayr B, Prieler R, Demuth M, Potesser M, Hochenauer C (2017) Computational analysis of a semi-industrial furnace fired by a flat flame burner under different $\mathrm{O} 2 / \mathrm{N} 2$ ratios using the steady laminar flamelet approach. J Energy Inst 90 (4):602-612.

https://doi.org/10.1016/j.joei.2016.05.002

28. Jóźwiak P, Hercog J, Kiedrzyńska A, Badyda K (2019) CFD analysis of natural gas substitution with syngas in the industrial furnaces. Energy 179:593-602. https://doi.org/10.1016/j.joei.2016.05.002

29. Rezazadeh N, Hosseinzadeh H, Wu B (2019) Effect of burners configuration on performance of heat treatment furnaces. Int J Heat Mass Transfer 136:799-807. https://doi.org/10.1016/j.ijheatmasstransfer.2019.01.113

30. Arkhazloo NB, Bouissa Y, Bazdidi-Tehrani F, Jadidi M, Morin J-B, Jahazi M (2019) Experimental and unsteady CFD analyses of the heating process of large size forgings in a gasfired furnace. Case Stud Therm Eng 14:100428. https://doi.org/10.1016/j.csite.2019.100428 31. Wang ZJ, Shang XF Flow and Heat-Transfer Simulation Based on CFD and Experimental Study during High-Pressure Gas Quenching. In: App Mech Mater, 2010. Trans Tech Publ, pp 1436-1440. https://doi.org/10.4028/www.scientific.net/AMM.29-32.1436

32. Macchion O, Lior N, Rizzi A (2004) Computational study of velocity distribution and pressure drop for designing some gas quench chamber and furnace ducts. J Mater Process Technol 155:1727-1733. https://doi.org/10.1016/j.jmatprotec.2004.04.335

33. Mevec DG, Raninger P, Prevedel P, Jászfi V (2020) A posteriori Reconstruction of the temperature Distribution in Surface Hardened tempering Steel. Scientific Reports 10 (1):1-8 
34. Revilla C, López B, Rodriguez-Ibabe J (2014) Carbide size refinement by controlling the heating rate during induction tempering in a low alloy steel. Mater Des (1980-2015) 62:296-304. https://doi.org/10.1038/s41598-020-63328-6

35. Liu B, Qin T, Xu W, Jia C, Wu Q, Chen M, Liu Z (2019) Effect of Tempering Conditions on Secondary Hardening of Carbides and Retained Austenite in Spray-Formed M42 High-Speed Steel. Materials 12 (22):3714. https://doi.org/10.3390/ma12223714

36. Kazeminezhad M (2013) Prediction of the mechanical properties of rods after cold forging and heat treatment. Int J Adv Manuf Technol 69 (9-12):2071-2079. https://doi.org/10.1007/s00170-013-5189-1

37. Ray P, Ganguly R, Panda A (2003) Optimization of mechanical properties of an HSLA-100 steel through control of heat treatment variables. Mater Sci Eng: A 346 (1-2):122-131. https://doi.org/10.1016/S0921-5093(02)00526-9

38. Wang J, Xu Z, Lu X (2020) Effect of the Quenching and Tempering Temperatures on the Microstructure and Mechanical Properties of H13 Steel. J Mater Eng Perform:1-11, https://doi.org/10.1007/s11665-020-04686-0

39. Wu B, Chen H, Shang C, Xie K, Misra R (2019) Effect of Tempering Mode on the Microstructure and Mechanical Properties of a Lean Alloy Martensitic Steel: Conventional Reheating Versus Induction Reheating. J Mater Eng Perform 28 (5):2807-2815. https://doi.org/10.1007/s11665-019-04072-5

40. Milosan I, Cristea D, Voiculescu I, Pop MA, Balat-Pichelin M, Predescu AM, Bogatu CA, Bedo T, Berbecaru A-C, Geantă V (2019) Characterisation of EN 1.4136 stainless steel heattreated in solar furnace. Int J Adv Manuf Technol 101 (9-12):2955-2964. https://doi.org/10.1007/s00170-018-3153-9 
41. Baukal Jr CE (2003) Industrial burners handbook. CrC press, London, USA.

42. Fluent A (2016) Theory Guide 17.2. Ansys Inc USA

43. Spalding D Mixing and chemical reaction in steady confined turbulent flames. In:

Symposium (International) on Combustion, 1971. vol 1. Elsevier, pp 649-657, New york, USA.

44. Ishii T, Zhang C, Hino Y (2002) Numerical study of the performance of a regenerative

furnace. Heat Transfer Eng 23 (4):23-33. https://doi.org/10.1080/01457630290090473

45. Magnussen BF, Hjertager BH On mathematical modeling of turbulent combustion with

special emphasis on soot formation and combustion. In: Symposium (international) on

Combustion, 1977. vol 1. Elsevier, pp 719-729. https://doi.org/10.1016/S0082-0784(77)80366-4

46. Versteeg HK, Malalasekera W (2007) An introduction to computational fluid dynamics: the finite volume method. Pearson education, Essex, England.

47. Raithby G, Chui E (1990) A finite-volume method for predicting a radiant heat transfer in enclosures with participating media. 112(2): 415-423, https://doi.org/10.1115/1.2910394

48. Smith T, Shen Z, Friedman J (1982) Evaluation of coefficients for the weighted sum of gray gases model. J. Heat Transfer, Vol 104: 602-608, https://doi.org/10.1115/1.3245174

49. Finkl Steel Inc. M, Saint-Joseph-de-Sorel, QC J3R 3M8, Canada.

50. https://www.tainstruments.com. 